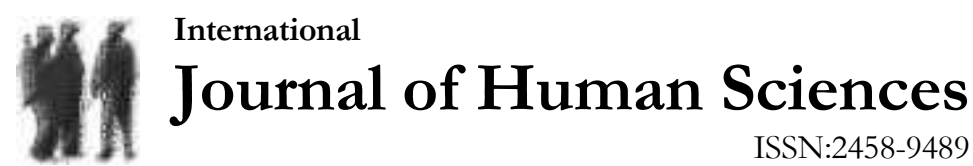

Volume 17 Issue 1 Year: 2020

\section{The importance and process of using theory in nursing researches}

\section{Hemşirelik araştırmalarında kuram kullanımının önemi ve süreci}

\author{
Ruveyde Aydin ${ }^{1}$ \\ Kamile Kabukcuoğlu ${ }^{2}$
}

Özet

Hemşirelik; temeli felsefe, kuram, araştırma ve uygulama üzerine kurulu bir sağllk disiplinidir. $\mathrm{Bu}$ sağlık disiplinin bilgi birikiminin oluşması, araştırma yöntemlerinin belirlenmesi, araştırma sürecinin sistematik olarak gerçekleştirilmesi ve uygulamaya aktarılması sürecine kuramlar 1 şık tutmaktadir. Kuramlar problemin belirlenmesinden, problemin çözüleceği ve bu çözümün uygulamaya nasıl aktarılacağı konusunda oldukça önemlidir. Bir bilginin bilimsel olabilmesi için sistematik temeller üzerine oluşturulmuş olması gerekmektedir. Profesyonel olarak hemşirelik mesleğinin ve eğitiminin gelişebilmesi için lisans ve lisansüstü eğitim kuram temelli olmalıdır. Meslek üyeleri lisans eğitiminde kuramları anlamalı içselleştirmeli, yüksek lisans eğitiminde kuram temelli araştırmalar yapmalı, doktora eğitiminde ise kuramları araştırma yoluyla denemeli ve yeni kuramların gelişimine katkı sağlamalıdır. Bu sayede, hemşirelik mesleğinin bilimsel temelleri daha da güçlenecektir. Bu derlemede hemşirelik araştırmalarında kuramların kullanım süreci, kuram kullanımının önemi ve sinırlliklarına ilişkin bilgi sunulmaktadır.

Keywords: Hemşirelik; Kuram; Model; Hemşirelik Araştırmaları.

(Extended English summary is at the end of this document)

\footnotetext{
1 Arş. Gör., Karadeniz Teknik Üniversitesi, Sağlık Bilimleri Fakültesi, Hemşirelik Bölümü, aydinruveyde@gmail.com

2 Prof. Dr., Akdeniz Üniversitesi, Hemşirelik Fakültesi, kkamile@akdeniz.edu.tr
} 
Aydın, R., \& Kabukcuoğlu, K. (2020). Hemşirelik araştırmalarında kuram kullanımının önemi ve süreci. Journal of Human Sciences, 17(1), 389-403. doi:10.14687/jhs.v17i1.5830

\section{Giriş}

Kuram sözcüğü Yunanca "görüş" anlamina gelen "theoria” sözcügünden gelmektedir. Türk Dil Kurumuna göre kuramın sözcük anlamı; "sistemli bir biçimde düzenlenmis birçok olayı açılayan ve bir bilime temel olan kurallar, yasalar bütünüdür (http://tdk.gov.tr/index.php).” Kuramlar, önermelerin bilimsel yöntem kullanilarak test edilmesi sonucu oluşan kavram topluluğudur (McEven, \& Wills, 2000; Fawcett, 2005; Alligood, \& Tomey, 2006). Kuramlar, araştırma sürecinin önemli bir parçasıdır (Meleis, 2007). Problemin belirlenmesinden, örneklemin seçilmesi, verilerin toplanmas1, veri analizinde kullanılacak yöntemin belirlenmesi ve bulguların yorumlanmasına kadar araştırma sürecine rehberlik etmektedir (Houser, 2008; Fawcett, 2012; İnan ve ark., 2013). Kuramlar araştırmalara rehberlik etmenin yanında, araştırmalar sonucu elde edilen bilginin formülüze edilmesini ve uygulamaya aktarılmasını sağlamaktadır (Polit, \& Beck, 2004; Houser, 2008; Macnee, \& McCabe, 2008).

Hemşirelik; temeli felsefe, kuram, uygulama ve araştırma üzerine kurulu bir sağlık disiplinidir. Bir işin profesyonel bir disiplin ve meslek olabilmesi için uygulamada kullanılabilecek sistematik birikmiş bir bilgi birikimine sahip olması gerekmektedir (Velioğlu, 1999). Uygulamaya aktarlabilen her bilginin temelini oluşturan kavram ve kuramlar vardır. Bu kavram ve kuramlar bilinçli kullanıldığı taktirde ilgili mesleğe ilişkin verilerin toplanması, analiz edilmesi ve sonuç olarak veri tabanının oluşmasını sağlar (Ay ve ark., 2007). Ancak bu durum, mesleğe özgü kuramların araşturmalar yolu ile oluşturulması, geliştirilmesi ve uygulamalarda kullanımı ile mümkün olabilmektedir (Polit, \& Beck, 2008).

Hemşirelikte araştırmanın tarihi Florance Nightingale dayanmaktadır. Nightingale araştırmaya önem vermiştir ve hemşireleri gerçeğin arayıcıları olarak tanımlamıştır (Velioğlu, 1999; Pfettscher, 2014). Hemşirelikte ilk araştırma kaynağı 1859'da Florence Nightingale'in 'Hemşirelik Notları" kitabıdır (Polit, \& Beck, 2008). Kitabında sağlıklı bireylerin bakımının hasta bakımından, koruyucu hijyenin de tıptan daha önemli olduğunu vurgulamıştır (Birol, 2004). Aynı zamanda, sağllğın iyileştirilmesinde çevrenin büyük bir öneme sahip olduğunu savunmuştur. Nigtingale araştırma konusunda kayıt, iletişim, düzen ve gözlemleme yeteneği, kavramlaştırma, analiz ve sentez üzerine yoğunlaşmıştır (Nightingale, 1993; Pfettscher, 2014). Nigtingale Kırım Savaşında askelerin mortalite ve morbiditesine neden olan durumları gözlemiş, veri toplamış ve analiz etmiştir. Burada yaptığı analiz yöntemi ile hemşirelik araştırmalarına büyük katkı sağlamıştır (Polit, \& Beck, 2008). Nightingale dönemi olan 1850 ve 1900 yllar arasında hemşirelik alanında temel düzeyde araştırmalar yapılırken, 1900 ve 1940 yılları arasında hemşirelik eğitimi ile ilgili araştırmalar yapılmıştır. 1923 yllında "Hemşirelikte Eğitim Araştırmaları" diye bir grup kurulmuştur ve bu grup hemşirelik eğitmenleri, halk sağllğ1 ve klinik hemşirelerinin eğitimi üzerine odaklanmıştur. Aynı zamanda bu grup "Goldmark" adında bir rapor yayınlayarak hemşirelik eğitiminin üniversite düzeyinde olması gerektiğini bildirmiştir (Polit, \& Beck, 2008). Hemşirelik araştırmalarının sayısı ve kalitesi 1952 yllında "The Journal of Nursing Research" dergisinin yayınlanmasına kadar çok yavaş gelişmiştir (Polit, \& Beck, 2008). Türkiye'de ise 1955 yllında Hemşirelik Yüksekokullarının açılması ile beraber hemşirelik araştırmaları başlamıştır (Velioğlu, 1999). Hemşirelik araştırmalarının tarihi gelişimi tablo 1'de gösterilmiştir.

Tablo 1. Hemşirelik araştırmalarının tarihi

\begin{tabular}{ll}
\hline Tarih & \multicolumn{1}{c}{ Olay } \\
\hline 1859 & Nightingale'in Hemşirelik Notları Kitabı yayınlanmıştır. \\
1900 & American Journal of Nursing yayına başlamıştır. \\
1923 & Columbia Üniversitesi ilk hemşirelik doktora programını kurmuştur. \\
1923 & "Goldmark" raporuyla hemşirelik eğitimi hakkında öneriler yayınlanmıstır. \\
1936 & $\begin{array}{l}\text { Sigma Theta Tau, Amerika Birleşik Devletleri'nde ilk hemşirelik araştırma ödülünü } \\
\text { vermiştir. }\end{array}$ \\
1952 & The Journal Nursing Research yayına başlamıştır.
\end{tabular}


Aydın, R., \& Kabukcuoğlu, K. (2020). Hemşirelik araştırmalarında kuram kullanımının önemi ve süreci. Journal of Human Sciences, 17(1), 389-403. doi:10.14687/jhs.v17i1.5830

1955 Hemşirelik araştırmalarına sponsor olmak için Amerikan Hemşireler Vakfı kurulmuştur.

1963 International Journal of Nursing Studies yayına başlamıştır.

1969 Canadian Journal of Nursing Research yayına başlamıştır.

1972 ANA Araştırma Komisyonu ve Hemşire Araştırmacılar Konseyi kurulmuştur.

1976 Journal of Advanced Nursing yayına başlamıştır.

1982 Hemşirelikte Araştırmanın Yürütülmesi ve Kullanımı projesi raporu yayınlamıştır.

1983 Annual Review of Nursing Research yayına başlamıştır.

1986 ABD Ulusal Sağlık Enstitüleri bünyesinde Ulusal Hemşirelik Araştırmaları Merkezi (NCNR) kurulmuştur.

1989 ABD Sağılk Politikası ve Araştırma Ajansı (AHCPR) kurulmuştur.

1993 Cochrane kurulmuştur.

1997 Kanada Federal Sağlık Hizmetleri ve Araştırma Vakfi kurulmuştur.

2000 Ulusal Hemşirelik Araştırmaları Enstitüsü yıllık finansmanı 100 milyon doları aşmıştır.

2000 Kanada Sağlık Araştırmaları Enstitüsü açılmıştır.

2014 Ulusal Hemşirelik Araştırmaları Enstitüsü yıllık finansmanı 140 milyon doları aşmıştır.

Nieswiadomy, R.M., \& Bailey, C.A. (2017). Foundations of Nursing Research. USA, Pearson Company, 1-6.

Amerikan Hemşireler Birliği (American Nurses Association-ANA) 1965 yllında kurularak hemşirelere araştırma yapmaları konusunda sponsor olmuştur. Aynı zamanda ANA 1972 yılında hemşirelik araştırmacıları birliğini kurmuştur. 1970’lerin başında hemşire bilimciler kendi kuramlarını ortaya koymaya başlamıştır. Giderek artan hemşirelik kuramcıları kendi modellerinin klinik uygulamalarda ve araştırmalarda test edilmesi için araştırmacılara gereksinim duymuşlardır. $\mathrm{Bu}$ araştırma çatısı içerisinde hemşirelik modellerinin kullanılmasını önerilmiştir ve bu sayede hemşireliğe özgü araştırmaların gelişmesini sağlamıştır. 1980’li yıllarda hemşirelik alanında kaliteli hemşirelik araştırmacılarının sayısı önemli derece artış göstermiştir. Araştırma metodları oluşturulmaya ve bilgisayar aracıllğıyla analizlerin yapılmaya başlanılmıştır (Polit, \& Beck, 2008). Kuramları kullanarak yapılan araştırmalardan elde edilen ve uygulamaya aktarılan bilgiler 1983 yılında Hemşirelik Araştırmaları Yıllığı (Annual Review of Nursing Research) olarak yayınlanmıştır. 1990’li yıllarda hemşireleri araştırma yapmalan için maddi olarak destekleyen çeşitli sağlık kuruluşları kurulmuştur ve bu destek 21. yüzyıla kadar sürmüştür (Polit, \& Beck, 2004).

\section{Araştırmalarda Kuram kullanımının Hemşireliğe Katkısı}

Kuram temelli çalsşma; deneyimler sonucu elde edilen bilginin analiz edilmesi, değerlendirilmesi ve kavramsallaşturllmasını içeren bir kritik düşünme sürecidir (Silva, \& Rothbart, 1984). Kritik düşünme; problemin tanımlanması, problemin nedenlerinin belirlenmesi, çözüm kaynaklarının değerlendirilmesi ve alternatif çözümlerin belirlenmesini içeren sistematik bir düzendir (Özer, 2002). Hızla gelişen sağlık teknolojileri içinde, hemşirelik uygulamalarının kritik düşünme çerçevesinde gerçekleştirilmesinin önemi her geçen gün artmaktadır (Alligood, 2014). Hemşirelik hizmetlerinde kanıt temelli uygulamaların artması, teknoloji ile birlikte bilgi ve uygulama yöntemlerindeki artıs bakımı çok boyutlu hale getirmekte ve hemşireleri kritik düşünmeye zorlamaktadır. Birçok durumu aynı anda düşünüp ve hızlı karar vermek zorunda olan hemşireler için kritik düşünme oldukça önemlidir (Özer, 2002). Kuramlar, hemşireler için klinik karar verme ve kritik düşünme sürecinde rehber görevi görmektedir (Scriven, \& Paul, 2004). Kuramlar, bir durumu etkileyebilecek faktörleri geniş bir perspektiften görmeye ve hedefe ulaşmak için en uygun yolları belirlemeye yardım etmektedir (Kaya ve ark., 2010). Araştırma ve uygulamada kuramların rehber alınması, hemşirelerin tıbbi uygulamalara değil hemşirelik rolü ve uygulamalarına odaklanmasına yardımcı olur. Aynı zamanda profesyoneller arasında koordinasyonu sağlayarak, uygulamalarda dil birliğini sağlar (Scriven ve Paul, 2004). Kuramlar hemşirelere, verdiği bakımın bireyin sağlı̆̆1 üzerindeki etkilerini değerlendirme, bu süreçte elde ettiği yüzlerce veriyi organize etme, analiz etme, yorumlama ve elde ettiği bilgiyi sistematik olarak açılama firsatı sağlar (Silva, \& Rothbart, 1984). 
Aydın, R., \& Kabukcuoğlu, K. (2020). Hemşirelik araştırmalarında kuram kullanımının önemi ve süreci. Journal of Human Sciences, 17(1), 389-403. doi:10.14687/jhs.v17i1.5830

Özetle verdiği bakımı değerlendirmesini ve çıktlara göre amaca ulaşıldığında bakımın durdurulması ya da ulaşılmadığı durumda bakımın sürekliliği sağlamaktadır. Aynı zamanda kuramlar profesyoneller arasında koordinasyonu ve uluslararası hemşirelik bakım standartları oluşturmasını sağlayarak uygulamalarda meydana gelen büyük farklılıkları ortadan kaldırır (Scriven, \& Paul, 2004).

\section{Hemşirelikte Araştırmalarından Kuram Kullanımının Önemi}

Disipline özgü bilgi üretimi ve birikimi probleme kuramlar ışığında karar vermek, problemin kuram temelli araştırmalar ile çözmek, kuramları test etmek ve geliştirmek ile gerçekleşebilmektedir. Kuram ve araştırma arasında karşlıklı dinamik bir süreç vardır: araştırma kuramı destekler, kuram araştırma sorusunu üretir ve araştırma sürecine rehberlik eder (Fawcett, 2005; McKenna, 2005; Parker, 2005). Jacox (1974) kuramsız araştırma yapmay1; "Kuram olmaksızın yapulan bir arasttrma, her biri birbirinden habersiz, tuğla ynğan plansız, tuğlacular takımına benzer. Tuğlacılar tuğlalar ynğn halinde atarlar ancak nasıl bir evin ortaya çıkacağından haberleri bile yoktur." cümlesiyle ifade etmiştir. Kuram olmaksızın üretilen hemşirelik bilgisi sadece tutarlı ve anlaşılır olmayan istatiksel ve gözlemsel verilerden oluşan bir bilgi yı̆̆ınıdır (Moody, 1996). Bilgi ne kadar çok olursa olsun, anlaşılmayan ve uygulamada kullanılmayan bilgi bir yığından ibarettir ve yalnızca çok az bir kısmı kullanılmaktadır. Bilgi araştırmalar yolu ile kazanılırken, kuramlar yoluyla anlaşıllı (Alligood, 2014). Bu karşllkklı ilişki şu şekil de anlatılabilir: Uygulamalar kuramların gelişimine yol açmalı, kuramlar araştırmalar yolu ile test edilmeli, geliştirilmeli, araştırmaya yol açmalıdır ve kuramlar araştırma ile uygulamaya tekrar dönmelidir.

Maalesef hemşirelikte kuram, araştırma ve uygulama arasındaki bu üçlü karşıllklı etkileşim yapısı eş zamanlı olarak işlev görmemektedir. Daha da kötüsü uygulamalar bir kuramı ya da araşturmayı rehber almadan gerçekleşmektedir. Hemşirelik araştırmalarının büyük kısmı tanımlayıcıdır. Kuramsal çalışmalar ise kuram ile zayıf bir şekilde bağlantılıdır ve herhangi bir kuramı rehber almadan çalş̧malar sürdürülmeye devam etmektedir (McKenna, 2005; Alligood, 2014).

Oliver Slevin'e (1996) göre "Kuram, araştırma ve uygulama üs dansçıder. Hepsi birbirinden etkilenir ve hepsi birbirinin ortaya çıkmasin sağlar. Dansçlar sistematik, estetik bir güzellik ve zerafet üretmek için etkileşime girer. Tökezlleyen veya uygun hareketler üstlenmeyen zaynf dansçı hareket edemez, ve diğerlerini olumsuz. etkiler. Böyle bir duru yolculuğun kisa sürmesine neden olur. Bu nedenle her üc dansçmın da gücllü ve yetenekli olması gerekir." Benzer şekilde zayıf teorili araştırmalar veya yetersiz araştırmalı uygulamalar bir disiplin olan hemşireliğin ölümüne neden olabilir. Bu üç dansçıyı güçlü tutmak ve uygun şekilde etkileşimde bulunmalarını sağlamak biz hemşirelerin görevidir (McKenna, 2005). Brown (1964) hemşire araştırmacıları araşturma planlarken; Bu araştırma teoriyle hangi bakımdan ve hangi ölçüde ilişkilidir? $\mathrm{Bu}$ araştırma, bilimsel bir bilgi birikimine ne gibi katkılar sağlar? sorularını sormaları gerektiğini vurgulamıştır.

Bazı bilim adamları araştırmaların kuram temelli olmaları gerektiğini belirtirken, bazı bilim adamları ise tüm çalışmaların kuram temelli olmak zorunda olmadığını bildirmiştir (Parker, 2005). Örneğin Fawcett ve Downs (1992) araştırmaların kuram temelli olması gerektiğini vurgularken, Chinn ve Kramer (2013) tüm araştırmalar kuram ile bağlantılı olmak zorunda olmadığını belirtmiştir. Araştırmalar, kuram ile bağlantılı ve kuram ile bağlantılı olmayan olmak üzere iki gruba ayrılmaktadır. Her ikisinin de mükemmel kalitede olabileceğini ve yeni bilgiye katkıda bulunabileceğini kabul etmektedirler. Ancak kurama dayalı çalışmalar yeni bilginin oluşturulmasında yüksek bir potansiyele sahip olduğunu vurgulamıştır (Chinn, \& Kramer, 2013). Kuram temelli araştırmalar; kuramın geliştirilmesi, değerlendirilmesi ve ya test edilmesi olmak üzere üç gruba ayırilmıştur (Fawcett, \& Downs, 1992).

Kuram geliştiren araştırmalar: Kuram geliştirme araştırmaları, olayları açıklamak ve keşfetmek amacıyla yapılmaktadır. Kuramlar tümevarım yaklaşımı ile ortaya çıkarılmaktadır. Bu nedenle araştırmacılar kuram üretme sürecinde, hemşirelik bakımının bilginin toplanması ve gözlenmesi için oldukça önemli olduğunun farkında olmalıdır. Kuramlar hem nitel araştırmalar hem de nicel araştırmalar yoluyla üretilebilirler (McKenna, 2005). 
Kuramı test eden araştırmalar: Kuram test eden araştırmalar var olan kuramın geçerliliğini belirlemek amacıyla yapılmaktadır. Kuram-test eden araştırmalarda araştırma yöntemleri, teorinin gerçek dünyadaki olguları ve ilişkilerini ne kadar doğru bir şekilde tasvir ettiğini araştırır. Kuram bir bütün olarak bir araştırma tarafindan test edilemez. Çünkü tüm kavramların ampirik göstergeleri yoktur (McKenna, 2005). Kuramın test edilmesi tümden gelim yaklaşımını içerir. Hipotezler randomize kontrollü araştırmalar ile test edilmelidir. Araştırma soruları veya hipotezler kuram içindeki kavramlardan türetilmelidir. Kavramsal yapı ile çalışma tasarımı arasında anlamlı tutarlı bir ilişkinin olması gerekmektedir. Araştırmacı kuram test eden bir araştırma yapıyor ise: Araştırma, hipotezleri/araştırma soruları ve kuram arasındaki ilişkileri gösterecek şekilde tasarlanmış mıdır? Araştırma kuram tarafindan destekleniyor mu? Kuram, temel araştırma soruları ya da hipotezler için bir bilgi kaynağı mı? sorularının yanıtını aranmalıdır (Fawcett, \& Downs, 1992). Tüm araştırmalarda olduğu gibi kuram test eden araştırmalarda da veri toplama araçları oldukça önemlidir. Seçilen örneklem dikkatlice seçilmeli ve örneklem büyüklügüu güç analizi yapılarak belirlenmelidir. Analizler, verilerin hipotezlerini desteklemek veya reddetmek için yeterli niceliksel kanıt sunup sunmadığına odaklanmalıdır (Parker, 2005).

Kuram temelli araştırmalar: Kuram temelli araştırmalarda amaç ne yeni bir kuram geliştirmek, ne de var olan kuramın geçerliliğini tespit etmek değildir. Burada amaç araşturmanın kavramsal çerçevesini ortaya koymak ve kuramsal çerçevesinin tartısılmasıdır. Aynı zamanda, araştırmanın tüm aşamalarını kavramsal bir çerçeveye oturtturmak ve bunu anlamlandırmaktır (Moody, 1990; McKenna, 2005). Polit and Hungler (1983) göre; kurama dayalı bir çalışmaya başlamadan önce aşağıldaki sorunların cevaplanması gerekmektedir:

-Araşturma sorusu ile kuramsal çerçeve arasında bir ilişki var mı?

-Kuramsal çerçeve ile çalışma arasındaki ilişki güçlü bir ilişki mi yapay bir ilişki mi?

- Alternatif teorik çerçeve daha uygun olur mu?

-Kuram mantıksal çerçeveye uygun mu? (Aktaran: Mc Kenna, 2005).

\section{Hemşirelikte Kuram Temelli Araştırma Süreci}

En iyi araşıırma süreci araştırma dizaynının adım adım olarak planlanması ile gerçekleşmektedir. $\mathrm{Bu}$ süreç, araştırma sorusunun belirlenmesi ve literatürün tanımlanması, kuramsal çerçevenin seçilmesi, varsayımların ve metodolojinin belirlenmesi ve seçilen metodoloji ile kuramsal çerçevenin ilişkilendirilmesi, verilerin toplanması, analizlerin yapılması, bulguların yazılması ve yorumlanmasını kapsar. Araştırma süreci fazı I, faz II, faz III, faz IV ve faz V olmak üzere beş adımdan oluşmaktadır (Şekil 1) (Clarke, 2010). 
Aydın, R., \& Kabukcuoğlu, K. (2020). Hemşirelik araştırmalarında kuram kullanımının önemi ve süreci. Journal of Human Sciences, 17(1), 389-403. doi:10.14687/jhs.v17i1.5830

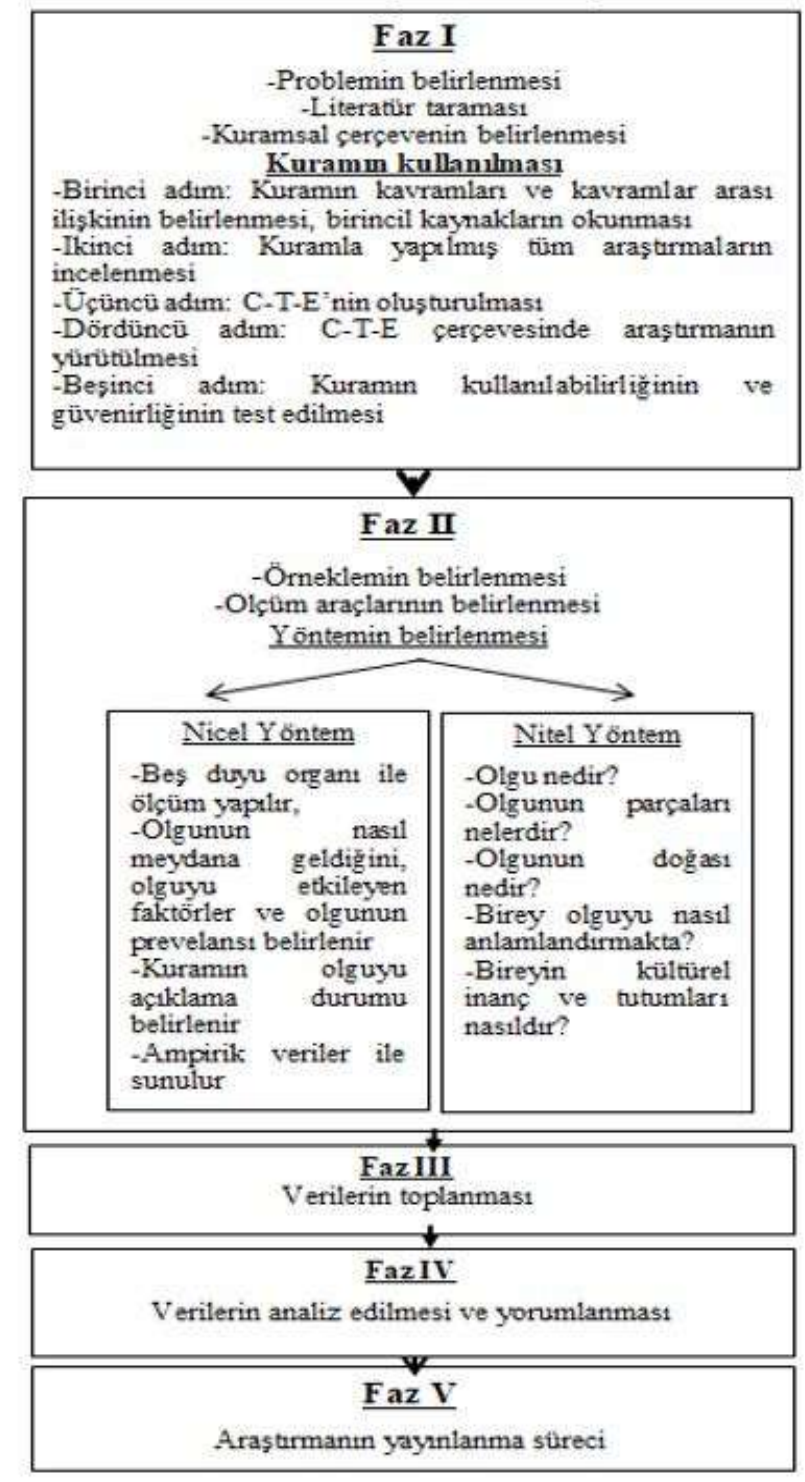

Şekil 1. Kuram temelli araştırmalarda araştırma süreci

Faz I: Araştırma probleminin belirlenmesi, literatürün taranması ve kuramsal çerçevenin belirlenmesi sürecini içermektedir.

Problemin belirlenmesi: Etrafımızda ya da çalışma alanımızda birçok problem vardır. Ancak her problem araştırma problemi olamamaktadır. Bir problemin araştırma problemi olabilmesi için belirli nitelikleri taşıması gerekmektedir. Bir araştırma probleminin çözülebilir, önemli, yeni, araştırılabilir, genellenebilir ve anlamlı olması gerekmektedir. Aynı zamanda araştırmayı yapacak kişinin alanda yeterli, yöntem ve teknik bilgide yetkin, veri toplama iznine, zaman ve imkân yeterliliğine sahip olması gerekmektedir. Bu nedenle bazen problemi bulmak problemi çözmekten daha fazla yetenek gerektirmektedir (Clarke, 2010).

Literatürün taranması: Araştırmanın fikir aşamasında, problemin ve çözüm sürecinin tanımlanmasında diğer araştırmalardan yararlanılmasıdır. Benzer araştırmaların incelenmesi hangi verilerin kullanıldığı, hangi yöntemin tercih edildiği, hipotezlerin nasıl test edildiği ve hangi analiz yöntemlerinin kullanıldığı ve sonuçların nasıl yorumlandığı hakkında yardımcı olacaktır (Fawcett, 2005). Problemin ve araştırma sürecinin tanımlanması sürecinde diğer kaynaklardan yararlanmaya "literatür taraması" denir. Literatür taraması ile daha sistematik, açık ve verimli bir araştırma süreci yönetilir (Parker, 2005). 
Kuramsal çerçevenin seçimi: Araştırmanın birinci fazının üçüncü süreci kuramsal çerçevenin seçimidir. Araştırmada kullanılacak kuramın seçilmesi probleme, problemde ele alınan kavramlara, kullanılacak ölçüm araçlarına ve örneklem grubuna bağlı olarak değişmektedir. Araştırmada kullanılacak kuramın uygunluğunda kuramın analiz edilmesi ve değerlendirilmesi gerekmektedir (Fawcett, \& Gigliotti, 2001). Seçilen kuramı analiz ederken; kuramcının öz geçmişi, kuramcının dünya görüşü, etkilendiği bilim insanları, kuramın varsayımları, kavramları, kuramın temelindeki felsefi inanç ve değerleri, kuramın hemşireliğin dört metaparadigması (insan, sağlık, hastalık, çevre) ile ilişkisi ve kuramla yapılan araştırmaların incelenmesi gerekmektedir (Fawcett, \& Gigliotti, 2001). Aynı zamanda araştırmacının araştırmasında kullanacağı kuramı seçerken şu sorulara yanit aramalıdır:

-Hemşirelik kuramı araştırmada kullanılmadan önce özel eğitim gerekli mi?

-Hemşirelik kuramının uygulama protokollerinin uygulamaya geçirilmesi hasta ve uygulanabilirlik açısından uygun mu?

-Hemşirelik kuramı hemşireliğin eğitim, araştırma ve uygulama alanlarında rehberlik etmede ne ölçüde kullanılabilir?

-Hemşirelik kuramı, farklı kültürel yapıya sahip insanların ihtiyaçlarını karşılayacak hemşirelik bakımına rehberlik edebilir mi?

-Hemşirelik kuramı araştırma problemini çözmede bana nasıl rehberlik edecek? (Fawcett, 2005).

Kuramın değerlendirme ve analizinden sonra probleme uygun olan kuram seçilir. Kuramın seçiminden sonra araştırmada kullanım süreci beş adımdan oluşmaktadır (Fawcett, \& Gigliotti, 2001, Çatal, \& Dicle, 2014).

Birinci adım: Kuramı geliştiren yazarın etkilendiği kişiler, kuramı oluşturmasının arkasında yatan felsefe, kuramın kavramları ve kavramları arasındaki ilişkinin ve kuramın varsayımlarının bilinmesi gerekmektedir. Bunu bilmenin en iyi yolu yazara ait kuramla ilgili birincil kaynakların okunmasidır (Fawcett, \& Gigliotti, 2001).

Íkinci adım: Aynı kuram kullanılarak yürütülen araştırmaların incelenmesidir. Bu incelemede araştırma probleminize en yakın ya da benzer araştırmaların incelenmesi oldukça önemlidir (Fawcett, \& Gigliotti, 2001). Araşturma sürecinize kuramın size nasıl rehberlik edeceğine dair önemli bilgiler sunacaktır. Aynı kuram kullanılarak yapılan araştırmaların araştırma sürecinize yol gösterici olması modeli içselleştirmenizi, modeli nasıl kullanacağınızı anlamanızı ve kullanılan istatistiksel yöntemlerin belirlenmesine önemli katkı sağlayacaktır (Fawcett, \& Gigliotti, 2001).

Üçüncü adım: C-T-E (Conceptual-Theoretical-Empirical) kuramın araştırmada kullanımında kavramsal, kuramsal ve deneysel yapının tanımlanmasıdır. Bu adımda kurama ait tüm kavramlar tanımlanmaktadır (Fawcett, \& Gigliotti, 2001). C-T-E sisteminin gelişimi ve yaygınlaştırılması hemşirelikte teori gelişimin bir göstergesidir (Fawcett, 2012). Hemşirelik disiplinine özgü C-T-E sistemlerinin kullanımı "hemşireliği otonom bir sağlık mesleği olarak ayırır" ve "hemşirenin kendine ve sağltk sistemine katkı sağlar." Özellikle hemşirelikte C-T-E sistemi hemşirelik bilgisine verilen bakımın koordineli olması, hemşirenin yaptığı uygulamayı düşünmesini ve değerlendirmenin doğru yapılmasını sağlamaktadır. Çünkü C-T-E sistemi hemşirelerin yapmış olduğu araştırmaların daha kapsamlı olmasını kuramların araştırma ve uygulamaya entegresyonunu kolaylaştırarak hemşireliğe farklı ve ortak bir dil kazandırmaktadır (Moody, 1990). C-T-E sistemleri, hemşirelik mesleğinde var olan bilgilinin doğruluğunun kontrol edilmesi, bilginin sadeleștirilmesi ve uygulanabilirliği sağlamaktadır. CTE kullanılmasının amacı, kanıta dayalı en iyi uygulamaya karar verilmesidir (Fawcett, 2005).

Dördüncü adım; C-T-E rehberliğinde araştırmayı sürdürmek ve uygulamayı gerçekleştirmektir.

Beşinci adım: Bu adım, kuram temelli gerçekleştirilen araştırmanın bulgularını sunmayı ve kuramın araştırma tarafindan desteklenip desteklenmediğini değerlendirmeyi içerir. Araştırma sonucu kuramı desteklemiyorsa kuramın araştırma temelli gerçekleştirip gerçekleştirilmediği ve deneyselliği sorgulanmalıdır. Buna ek olarak kuramın araştırmada kullanım uygunluğunun güçlü ve zayıf yönleri değerlendirilmelidir (Fawcett, \& Gigliotti, 2001). 
Yazarlardan Prof. Dr. Kamile Kabukcuoğlu'nun danışmanllğında yürütülen doktora tez çalışmasında kullanılan Meleis’in Geçiş teorisi bu adımlara göre incelenmiştir (Körükcü, \& Kukulu 2015).

Birinci adım: Kavramsal modelin içeriğidir; kuramın gelişim süreci, kuramcının etkilendiği teorisyen ya da bilim insanları, kuramcının felsefesi, kuramın varsayımları, kavramları ve kavramlar arası ilişki ayrıntılı olarak incelenmiştir.

Geçiş teorisinin ilk temelleri Meleis'in kronik hastalı̆̆ olan bireylere bakım veren eşlerin hastalar ya da çocukları ile iletişim ve etkileşimini tanımlayan yüksek lisans tezine dayanmaktadır. Doktora tezinde ise, kronik hastalıklar ile baş eden ailelerde eşlerin rollerinin tanımlanması ve ailenin geleceğini ilisskin planlar yapabilmesi için hemşirelik girişimlerine odaklanmıştır. Hem doktora tezinde hem yüksek lisans tezinde bireylerin hemşireye duydukları gereksinimler konusunda edindiği klinik deneyimler Meleis’in teorisinin gelişimine katk1 sağlamıştır.

Geçiş teorisinin felsefesine baktı̆̆ımızda; Meleis Geçiş Teorisi'nde Florance Nightingale'in çevre, sağllk ve iyiliğe olan ilgisinden etkilendiğini vurgulamıştır. Meleis’in hemşirelik, sosyoloji, rol teori ve ilgili geçmiş deneyimleri ve eğitimi teorisinin oluşumuna katkı sağlamıştır. Geçiş teorisi hakkında yapılan tüm araştırmalar teorinin şekillenmesini sağlamışır (Meleis, 2000; Meleis, 2010). Geçiş Teorisi özellikle antropolojiden etkilenerek geliştirilmiştir. Van Gennep'in "Geçitler töreni”" isimli çalışması Meleis’in teorisinin temelini oluturmuştur (Meleis, 2010). Meleis, hastalıkların bireylerin büyüme ve gelişmesi için bir firsat olduğundan bahseden Peplau'dan etkilenmiştir. Aynı zamanda, Meleis bireyin hastalıklardan bir anlam bulmasını sağlayan Travelbee'den ve Roy'un Adaptasyon Teorisi'nden etkilenmiştir. Orem'in teorisinin ana kavramı olan öz bakım kavramı, geçiş için önemlidir (Meleis, 2010).

Geçiş Teorisinin varsayımları nelerdir diye baktığımızda; Geçişler karmaşık ve çok boyutludur, tüm geçişler zaman içerisinde bir akış ve hareketlilik gösterir, geçişler kimlik, rol yetenek ve davranışlarda değişikliklere neden olur (Meleis, 2010).

Meleis'in Geçiş Terorisi'nin ana kavramı geçiştir. Geçişin; gelişimsel, durumsal ve kurumsal olmak üzere çeşitleri bulunmaktadır. Geçişler; tekil, çoğul, eş zamanlı, ilişkili ve ilişkisiz olarak meydana gelebilmektedir. Gelişimsel geçişler; bireyin büyüme ve gelişim sürecinde yaşadığı normal bir süreçtir. Durumsal geçişler; rollerdeki değişime ilişkin ani değişiklileri içerir ebeveyn olma gibi. Sağlık hastalık geçişi ani değişimler ya da aşamalı değişimler halinde gerçekleşebilmektedir. Örneğin; akut bir durum olan grip olma ani olarak gerçekleşirken, kronik bir hastlalık olan böbrek yetmezliği aşamalı ve geç meydana gelmektedir. Geçişin kolaylaştırıcıları ve engelleyecileri bulunmaktadır (Körükcü, \& Kukulu, 2014). Bunlar bireysel (kültür, anlam hazır olma vb.), toplum ve topluluk kaynaklı olabilmektedir. Geçişe gösterilen yanıt; sürecin gösterleri ve sonuçtur. Sürecin göstergelerinde geçişi etkileyen durumlar bağlanma hissi, etkileşim, yer ve konum, özgüven ve baş etmenin gelişimidir. Sonuçlar ise, uyumlanabilme, yeterlilik ve kimlik kazanımıdır. Teröpatik hemşirelik bakımı, fiziksel, psikolojik ve spiritual bakımı içermektedir (Şekil 2). Teröpatik hemşireliğin amacı; sağlık geçiş sürecini hızlandırmak ve kolaylaştırmak, hastalık geçişine engel olmak ya da azaltmaktır (Meleis, 2010). 
Aydın, R., \& Kabukcuoğlu, K. (2020). Hemşirelik araştırmalarında kuram kullanımının önemi ve süreci. Journal of Human Sciences, 17(1), 389-403. doi:10.14687/jhs.v17i1.5830

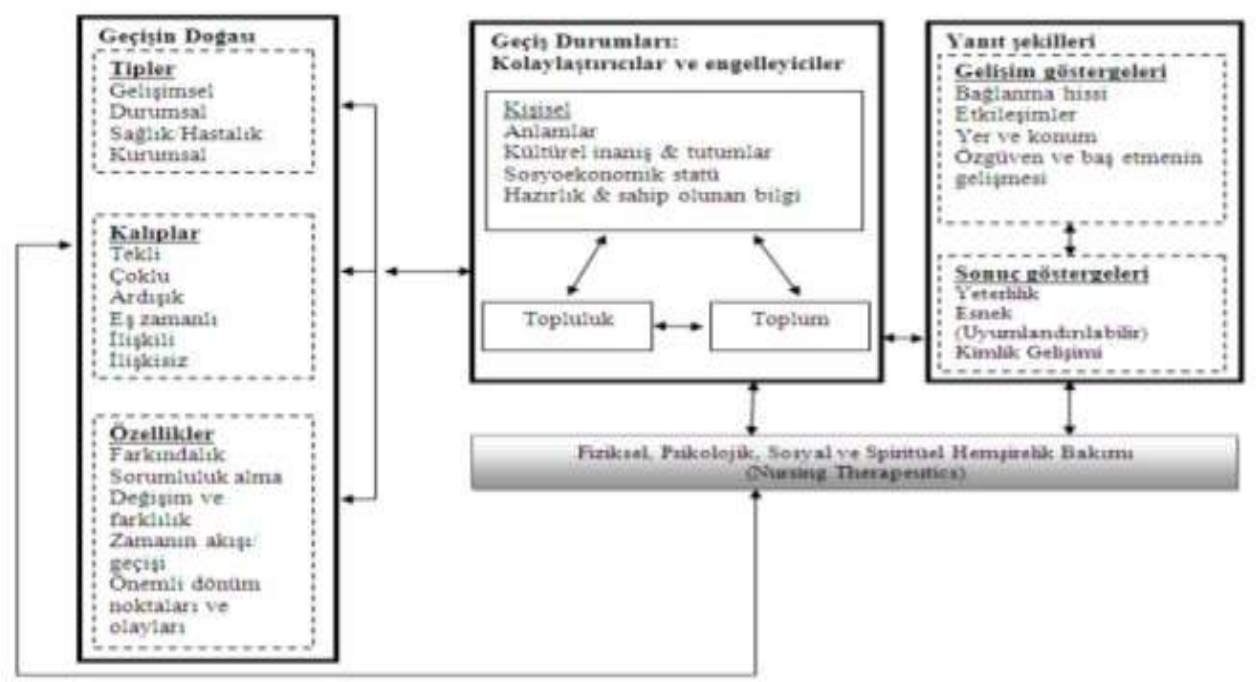

Şekil 2. Meleis'in Geçiş Teorisinin Kavram Haritası

Körükcü, Ö. (2015). Preterm Erken Membran Rüptürü Olan Gebelerde Meleis'in Geçiş Teorisine Göre Yapılandirlmış Farkindahk Programmin Anneliğe Geçiş Sürecine Etkisi. (Doktora Tezi, Danışman: Kamile Kabukcuoğlu) Akdeniz Üniversitesi/ Sağlık Bilimleri Enstitüsü, Hemşirelik Bölümü, Antalya.

Íkinci adım: Meleis'in birincil kaynağı olan ve aynı kuramı kullanarak araştırmalardan oluşan "Transitions Theory" kitabındaki araştırmalar incelenmiştir ve teorinin uygulanabilirliği görülmüş̧ür. Doktora tez konusu olan erken merman rüptürü olan gebelerde anneliğe geçiş süreci hakkında tekrar literatür taranmıştır. Yapılmış 310 tane çalışma bulunmaktadır. 101 çalışma gelişimsel geçiş, 100 çalışma durumsal 69 hastalık sağlık geçiş, 40 tanesi kurumsal geçiş hakkındadır. Diğerlerinin ise tam metnine ulaşılamadığı için geçiş tipi bilinmemektedir (Bohner, 2017).

Üçüncü adım: C-T-E (Conceptual-Theoretical-Empirical) kuramın araştırmada kullanımında kavramsal, kuramsal ve deneysel yapının tanımlanmasıdır. Bu adımda; preterm erken membran rüptürü olan gebelerde Meleis’in Geçiş Teorisi'ne göre yapılandırılan farkındalık programının gebeliğin kabulü, annelik rolünün kabulü, anneliğe hazır oluş ve eşi ile ilişkisinin durumu, maternal bağlanma ve postpartum kendini değerlendirme üzerine etkisinin incelendiği doktora tez çalışmasının konusu ve genel çerçevesi belirlendikten sonra kavramsal-teorik ve deneysel yapıyı oluşturmak için araştırma süreci modele göre yeniden değerlendirilmiştir. Doktora tez çalışmasının amac1; "Preterm erken membran rüptürü olan gebelerde Meleis'in Geçis Teorisi'ne göre yapulandirlan farkındalı programınm annelïge geçis sürecine etkisini belirlemektir." Tez çalışmasinda kullanılan ölçek ve ölçek alt boyutlarının teorinin hangi kavramlarını karşıladığ1 tablo 2'de belirtilmiştir (Körükcü, 2015; Körükcü, \& Kukulu, 2017).

Tablo 2. Teorinin kavramları ve doktora tez çalışmasında karşıladığı durum

\begin{tabular}{ll}
\hline \multicolumn{1}{c}{ Teorinin kavramları } & \multicolumn{1}{c}{ Tezdeki karşıladığı durum } \\
\hline Gelişimsel geçiş & Gebeliğe ve anneliğe geçiş \\
Sağlık/Hastalık geçişi & Erken merman rüptürü \\
Durumsal geçiş & Hastaneye geçiş \\
Anlamlar & $\begin{array}{l}\text { Postpartum Kendini Değerlendirme Ölçeği Doğuma hazır oluş alt boyutu } \\
\text { Postpartum Kendini Değerlendirme Ölçeği Gebeliğin kabulü alt boyutu }\end{array}$ \\
& $\begin{array}{l}\text { Postpartum Kendini Değerlendirme Ölçeği Annelik rolünün kabulü alt } \\
\text { boyutu }\end{array}$ \\
Sosyo-ekonomik durum & Sosyoekonomik durumun belirlenmesi \\
Hazırlık-sahip olunan bilgi & Emzirme ve bebek bakımı konunda bilgi düzeyinin belirlenmesi \\
Topluluk & Postpartum Kendini Değerlendirme Ölçeği Eşi ile ilişkisinin durumu alt \\
& boyutu \\
\hline Teröpatik hemşirelik bakımı & Farkındalık temelli hemşirelik bakımı \\
\hline
\end{tabular}


Kuram temelli araştırmalarda kuramın kavramlarının tümünü incelemek ya da araştırmak mümkün olamamaktadır. Bu tez çalışmasında kavramlarının birçoğu incelenmeye çalışılmıştır.

Dördüncü adım: C-T-E rehberliğinde tez çalısması sürdürülmüştür ve uygulama gerçekleştirilmiştir (Şekil 2).

Beşinci adım: Yukarıda bahsedildiği gibi bu adımda; kuram temelli gerçekleştirilen araştırmanın bulgularını sunmayı ve kuramın araştırma tarafindan desteklenip desteklenmediğini, kuramın araştırmada kullanım uygunluğunun güçlü ve zayıf yönleri değerlendirilir (Fawcett, \& Gigliotti, 2001). Meleis geçiş teorisinde hemşire ve çevre-insan etkileşiminin kapsamlı sonuçlarına değinmiştir. Teoride basitlik; kavramların sayısı ve birbiri ile olan ilişkisini ifade etmektedir. Geçiş teorisi basit bir teori değildir (Bohner, 2017). Geçiş teorisinin 15 kavramı bulunmaktadır ve maksimum ilişki sayısı 26'dır (Melesi ve ark., 2000). İstenen kavramlar arası ilişkinin, 15'den fazla olmamasıdır (Bohner, 2017). Bir teorinin yapısı resmedilmiş ve oklar ile ilişkiler gösteriliyorsa etkileyen ve etkilenen taraf gösterilmelidir. Aynı zamanda bu etkilenmenin negatif mi pozitif mi olduğu + ve - ile gösterilmelidir. Geçiş Teorisinde kavramlar arası ilişki oklarla gösterilmiştir. Ancak bu ilişki pozirif mi? negative mi? belirtilmemiştir (Bohner, 2017). Bunlara rağmen, Meleis'in Geçiş Teorisi birçok araştırma tarafindan desteklenmiştir ve kültüre uygun olduğu belirlenmiştir (Meleis, 2010; Bohner, 2017).

Faz II: Faz II'de araşturmanın yöntemi belirlenmektedir. En uygun yöntem ve örneklemin ne olduğuna, veri toplama araçlarına, verilerin nerede, ne zaman ve hangi koşullar altında toplanacağına karar verilir. Araştırmacılar veri toplayacağı araştırma araçlarının geçerlik ve güvenirliği yapılmış, psikometrik özelliği yüksek olan araçları seçmelidir (Fawcett, 2005). Geçmişten bu güne kadar pozitivistler ve postpozitivistler arasında araştırma yöntemleri hakkında çatışma yaşanmaktadır. Pozitivistler nicel araştırma yöntemlerini kullanırken, postpozitivistler nitel araştırma yöntemlerini savunmaktadır. Pozitivistler var olan problemi etkileyen faktörleri görme, duyma, dokunma ve koku yoluyla tespit etmeye çalışırlar ve genellikle bir ölçüm aracı kullanırlar (Peca, 2000). Nicel araşturmalar; olgunun prevelansına, olgunun nasıl meydana geldiğine, olguyu etkileyen faktörlere, olgunun kaynağının ne olduğuna odaklaklanmaktadır. Nitel araştırmalar ise; Olgunun adı nedir? Olgunun parçaları nelerdir? Olgu hakkındaki en önemli şey nedir? Olgunun doğası nedir? Olgunun anlamı nedir ve nasıl meydana gelir? sorularının cevabına odaklanmaktadır (Fawcett, 2005; İbrahimoğlu, 2011).

Bir pozitivist olan Kant'a göre olgunun anlaşılması için kanıt temelli araşturılabilen geçerliliği test edilen araştırmaların yapılması ve evrensel kuralların konulması gerektiğini vurgularken, Kuhn'a göre ise sadece nicel çalışmalar ile olgunun kaynağına ulaşılamaz, olguyu etkileyen bireyin değer ve kültürel inançlarıdır (Kuhn, 1982). Bir olguyu araştırırken bunlar göz ardı edilemez. Bir araştırma yapılırken araştırma; araştırmacının düşünce, alg1 ve değerlerinden etkilenmektedir. Bu nedenle Kuhn pozitivist yaklaşımın revize edilmesi gerektiğini Kant'ın pozitivizmden ayrilarak postpozitivizm yaklaşımını benimsemesi gerektĭgini vurgulamıştır (Polit, \& Beck, 2004; Sönmez, 2011).

Faz III aşama verilerin toplama aşaması iken, Faz IV verilerin analiz aşamasıdır. Verilerin analizinde ilk olarak tanımlayıcı istatistikler yapılırken, ikinci olarak gruplar arası farklıllğı ortaya koymak için ilişkisel istatistiksel analizler yapilır. İlişkisel analizler araştırmanın en önemli yeridir ve uygulama yapılan müdahale grubu ile kontrol grubu arasındaki farklllkları ortaya koyar. Bu gibi basit istatistiklerden sonra aslında diğer araştırmalardan farkı ortaya koymak ve araştırmayı güçlendirmek için ileri düzey analizler yapılmalıdır (çoklu regresyon, yapay sinir ağları, yapısal eşitlik modeli vb.). Araştırma sürecinin son aşaması $\mathbf{F a z} \mathbf{V}$ ise araştırmanın yayınlanma aşamasıdır (Clarke, 2010). 
Aydın, R., \& Kabukcuoğlu, K. (2020). Hemşirelik araştırmalarında kuram kullanımının önemi ve süreci. Journal of Human Sciences, 17(1), 389-403. doi:10.14687/jhs.v17i1.5830

\section{Hemşirelikte Kuram Kullanımının Sınırlılık Nedenleri}

Hemşirelik araşurma ve uygulamalarında, kuram kullanımı hemşirelik disiplinine birçok katkı sağlamasına rağmen, kuram kullanımı oldukça sınırlıdır. Bunun birçok nedeni bulunmaktadır: -Hemşirelik disiplininin genç olması (McEwen, \& Willis, 2006),

-Kuramların çoğunun karmaşık yapılara sahip olması ve soyut kavramlardan oluşması,

-Bazı kuramların araştırmalar yoluyla geliştirilmemesi,

-Hemşirelerin eğitimlerinden dolayı felsefik düşünme kabiliyetlerinin gelişmemesi ve buna bağlı olarak soyut bir yapiya sahip olan kuramları yeterince anlayamamalar1,

-Klinisyen hemşireler ve araştırmacı hemşireler arasında kopukluğun olması,

-Aynı zamanda klinisyen hemşirelerde yabancı dil probleminin olmasıdır (Parker, 2010).

\section{Hemşirelikte Kuram Temelli Araştırma ve Uygulamaları Artırmak İçin Yapılması Gerekenler}

Kuramların uygulamaya aktarılabilmesi için kuram temelli araştırmaların uygulamaya aktarılması ve uygulamaların tekrar araştırlarak değerlendirilmesi gerekmektedir (Fawcett, 2005). Hemşireler arasında dil ve uygulama birliğinin sağlanabilmesi için ise hemşirelik eğitiminde kuramların öğretilmesi oldukça önemlidir (Fawcett, 2005; Parker, 2010). Lisans eğitiminden başlayarak lisansüstü eğitime kadar hemşirelik eğitiminin her düzeyinde kuram temelli araşturma ve uygulamalara yer verilmelidir. Bu nedenle hemşirelik lisans eğitiminin kuram temeline dayandırılarak gerçekleştirilmesi ve yüksek lisans eğitiminde devamlılığının sağlanarak öğrencilerin kuramları ve kuram temelli araştırma yöntemlerini içselleştirmesi sağlanmalıdır (Meleis, 2007). Bu içselleştirme doktora eğitiminde kuramların kültüre ve örnekleme uygunluğunu test etme ve yeni kuramların oluşturulmasına ön ayak olarak; hemşirelikte bilimsel bilginin gelişimine büyük katkı sağlayacaktır (Meleis, 2007).

Hemşirelik tezlerinde kuram temelli çalışmanın mesleki gelişim için sağladı̆̆1 yararların yanında bireysel olarak da kuram temelli çalışan öğrencilerin mesleki bilgisi artmakta, bu öğrenciler hemşirelik paradigmasını daha iyi benimsemektedir. Aynı zamanda bu öğrenciler daha iyi sentez ve analiz etmektedirler. Doktora tezi yapan kişilerin gelecekte hemşire akademisyenler olacakları düşünülürse, yeni yetişen hemşirelerin doğru yönlendirilmesi ve akademisyen hemşirelerin daha donanımlı olmasına da katkı sağlayacağı düşünülmektedir (Alligood, 2014).

\section{Türkiye'de Hemşirelik Araştırmalarında Kuram/Model Kullanım Durumunun İncelenmesi}

Hemşirelik araştırmalarında kuram ve model kullanımının, yararları birçok kaynakta belirtilmektedir. Ancak ülkemizde kurama temellendirilmiş araştırma sayısı yeterli değildir. Ekim ve arkadaşlarının (2012) yaptığı çalışmada 2000-2011 yılları arasında ülkemizde yapılan hemşirelik araştırmaları kuram kullanımı açısından değerlendirmiş; toplamda 3910 araştırma incelenmiş ve bu araştırmaların \%3.5 ( $\mathrm{n}=137$ )'unda hemşirelik ya da hemşirelik dışı teori kullanıldığı belirlenmiştir. Dergilerde yayınlanan araştırmaların büyük çoğunluğunun doktora tezleri olduğu saptanmıştır. Araştırmalarda, en fazla Orem'in Özbakım Eksikliği Teorisi ve Pender’in Sağlığı Geliştirme Modeli kullanıldığı bulunmuştur. İnan ve arkadaşlanının (2013) yaptığ1 çalışmada, 1995-2010 yılları arasında kuram ya da modele dayanarak yapılmış 48 hemşirelik araştırmasına ulaşılmıştır. Araştırmalarda kuram kullanımının sınırlı olduğu ve kuramın araştırma sürecinin tüm basamaklarında yer almadığ1 ve kuram kullanım basamakları doğrulturultusunda olmadığı saptanmıştır.

Tezlerde kuram ve modeller üzerine çalışmanın bazı zorlukları ve kolaylıkları bulunmaktadır. Mete ve Gökçe İşbir'in (2005) yapmış olduğu nitel çalışmada, doktorada kuram üzerine temellendirilmiş tez çalışması yürüten 10 doktora öğrencisi ve 5 tez danışmanı ile derinlemesine görüşmeler yapılmıştır. Görüşmelerde; neden kuram temelli çalıştıkları ile kuram üzerine çalışmayı zorlaştıran ve kolaylaştıran faktörler sorulmuştur. Katılımcilar kuram ve model üzerine çalışmalarının nedeni olarak; tezlerdeki son yönelimin böyle olduğunu ve mesleki profesyonel bilgiye, tezin yöntemine, hemşirelik okulu ve hemşirelik öğrencilerinin gelişimine katkı sağladığı için 
çalışıklarını belirtmişlerdir. Öğrenciler teori temelli çalışmanın zorluklarını; çalışılan modeli anlamada güçlük yaşamak, modelin gereksiz olduğuna inanmak ve modelle ilgili yayınlanan makale sayısının yetersiz olması olarak ifade etmişlerdir. Öğrenciler kolaylaştırıcı faktörleri ise; daha önce modelle ilgili çalışan araşturmacılardan alınan yardımlar, aynı model üzerine çalışan doktora öğrencilerinin bilgi paylaşımı ve danışmanın doğru ve yeterli yönlendirmesi olarak belirtilmiştir.

Yazarlar tarafindan yapılan değerlendirmede; Türkiye'de hemşireler tarafindan kuram/modele dayalı olarak yapılmış tezler incelenmiştir ve 2000-2019 yılları arasında 171 lisansüstü teze ulaşılmıştır. Tezlerde: Doroty E. Johnson'ın Davranışsal Sistem Modeli, Sosyal Bilişsel Öğrenme Kuramı, Roy Uyum Modeli, Orem Özbakım Eksikliği Hemşirelik Teorisi, Pender'in Sağllğı Geliştirme Modeli, Watson İnsan Modeli, Meleis’in Geçiş Teorisi, Leininger Kültürel Bakımda Farklılıklar Modeli, Kolcaba'nın Konfor Kuramı, Neuman Sistemler Modeli, Piaget'nin Bilişsel Gelişim Kuramı, Levine'nin Koruma Modeli, Transteoretik Model, Precede Modeli, Sağlık Davranışı Etkileşim Modeli ve Sağlık İnanç Modelinin kullanıldığı görülmüştür.

\section{Sonuç}

Hemşirelik mesleğinin ve eğitiminin gelişimine katk1 sağlamak için hemşirelik araştırmalarında ve lisansüstü tezlerinde; hemşirelik kuram ve modelleri kullanılmalıdır. Hemşirelik lisansüstü eğitiminde, mesleki bilginin üretilmesi ve mesleğe katkı sağlanması için kuram ve model kullanımı daha da yaygınlaştırılmalıdır. Kuram ve modellerin araştırma ve uygulamaya adaptasyonunu sağlayabilmek için hemşirelerin hemşirelik kuramlarına hakim olması oldukça önemlidir. Bunun için, hemşirelik lisans eğitiminde kuram dersi verilmeli, yüksek lisansta kuram temelli araştırmalar yapılmalı ve doktora eğitiminde kuramlar geliştirilmelidir.

\section{Kaynaklar}

Alligood, M.R., \& Tomey, A.M. (2006). Nursing Theory; Ultilization \& Application. America, Mosby, 307-333

Alligood, M.R. (2014). Areas for Further Development of Theory Based Nursing Practice "Alligood MR, Tomey AM (eds), Nursing Theory; Utilization \& Application. America, Elsevier, 414-424

Ay, F. (Editör), Ertem, Ü., Özcan, N., Ören, B., Işık, R., \& Sarvan, S. (2007). Temel Hemşirelik Kavramlar, Ilkeler, Uygulamalar. Istanbul, Medikal Yayıncilik, 5-6.

Bohner, K. (2017). Theory description, critical reflection, and theory evaluation of the transitions theory of Meleis et al according to Chinn and Kramer (2011). Advances in Nursing Science, 40(3), E1-E19.

Birol, L. (2004). Hemşirelik Süreci: Hemşirelik Bakımında Sistematik Yaklaşım. Ankara, Etki Matbaacilik Yayincilik, 35-45.

Brown, M.I. (1964). Research in the Development of Nursing Theory: The Importance of a Theoretical Framework in Nursing Research. Nursing Research, 13(2):109-112.

Chinn, P.L., \& Kramer, M.K. (2013). Integrated Theory \& Knowledge Development In NursingE-Book. America, Elsevier, 1-15.

Clarke, S. (2010). Research in Nursing. Theory and Reasoning in Nursings. Amerika, Lippincott Williams \& Wilins, 150-200.

Cody, W.K. (2006). Philosophical and Theoretical Perspectives for Advanced Nursing. Boston, Jones and Bartlett Publishers, 43-44.

Çatal, E., \& Dicle, A. (2014). Teori-Araşturma Bileşeni: Roy’un Uyum Modeli Örneği. Dokuz Eylül Üniversitesi Hemşirelik Fakültesi Elektronik Dergisi, 7(1), 33-45.

Ekim, A., Manav, G., \& Ocakço, A.F. (2012). Ülkemizde Teori Temelli Hemşirelik Araştırmaları: Bir Gözden Geçirme. Dokuz Eylül Üniversitesi Hemşirelik Yüksekokulu Elektronik Dergisi, 5(4): 157-161. 
Aydın, R., \& Kabukcuoğlu, K. (2020). Hemșirelik araştırmalarında kuram kullanımının önemi ve süreci. Journal of Human Sciences, 17(1), 389-403. doi:10.14687/jhs.v17i1.5830

Fawcett, J. (eds). (2005). Contemporary Nursing Knowledge Analysis and Evoulation of Nursing Models and Theories. Philadelphia, FA Davis Company, 364-437.

Fawcett, J. (eds). (2012). Contemporary Nursing Knowledge Analysis and Evoulation of Nursing Models and Theories. Philadelphia, FA Davis Company, 27.

Fawcett, J., \& Downs, F.S. (1992). Conceptual Models, Theories, and Research. The Relationship of Theory and Research. Philadelphia, FA Davis Company, 101-115.

Fawcett, J., \& Gigliotti E. (2001). Using Conceptual Models of Nursing to Guide Nursing Research: The Case of the Neuman Systems Model. Nursing Sciences Quarterly, 14(4):339345.

Houser, J. (eds). (2008). The Importance of Research as Evidence in Nursing. In Nursing Research: Reading, Using and Creating Evidence. Sudbury, Jones and Bartlett Publisher, 3-8.

İbrahimoğlu, Z. (2011). Değişen Paradigmalar Dünyasından Nitel ve Nicel Araştırmalara Bakmak: Felsefi Yaklaşımlardaki Dönüşümü Anlamak. Çukurova Üniversitesi Eğitim Fakültesi Dergisi, 1(40): 44-52.

İnan, F., Üstün, B., \& Bademli, K. (2013). Türkiye'de Kuram/Modele Dayalı Hemşirelik Araştırmalarının Incelemesi. Anadolu Hemşirelik ve Sağlık Bilimleri Dergisi, 16(2):132-139.

Jacox, A. (1974). Theory Construction in Nursing: An Overview. Nursing Research, 23(1): 4-12.

Kaya, N., Babadă̆, K., Yeşiltepe, Kaçar, G., \& Uygur, E. (2010). Hemşirelerin Hemşirelik Model/Kuramlarını, Hemşirelik Sürecini ve Sınıflama Sistemlerini Bilme ve Uygulama Durumları. Maltepe Üniversitesi Hemşirelik Bilim ve Sanatı Dergisi, 3(3):24-33.

Körükcü, Ö., \& Kukulu, K. (2017). The Effect of the Mindfulness-Based Transition to Motherhood Program in Pregnant Women with Preterm Premature Rupture of Membranes. Health Care for Women International, 38(7), 765-785.

Körükcü, Ö., \& Kukulu, K. (2014) Preterm Erken Membran Rüptürü Olan Gebelerin Anneliğe Geçişlerinin Meleis'in Geçiş Teorisine Göre İncelenmesi. Anadolu Hemşirelik ve Sağllk Bilimleri Dergisi, 17(4).

Körükcü, Ö. (2015). Preterm Erken Membran Rüptürü Olan Gebelerde Meleis'in Geçis Teorisine Göre Yapılandirlmus Farkındalık Programmm Anneliğe Geçiş Sürecine Etkisi. (Doktora Tezi, Danışman: Kamile Kabukcuoğlu) Akdeniz Üniversitesi/ Sağlık Bilimleri Enstitüsü, Hemşirelik Bölümü, Antalya.

Macnee, C.L., \& McCabe, S. (eds.) (2008). Understanding Nursing Research. In Evidence-Based Nursing: Using Research in Practice. Philedelphia, Lippincott Williams \&Wilkins, 5-22.

Meleis, AI. (2010) Transitions Theory: Middle-Range and Situation-Specific Theories in Nursing Researchand Practice. New York, Springer Company.

Meleis, A.I., Sawyer, L.M., Im, E., Messias, D.K.H., \& Schumacher, K. (2000). Experiencing Transitions: An Emerging Middle-Range Theory. Advance Nursing Sciences. 23(1), 12-28.

Meleis, A.I. (eds). (2007). Theory: Metaphors, Symbols, Definitions. In Theoretical Nursing: Development \& Progress. Philedelphia, Lippincott Williams \& Wilkins, 45-48.

Mete, S., Gökçe, \& Issbir, G. (2005). Using a Nursing Theory or a Model in Nursing Phd Dissertations: A Qualitative Study from Turkey. International Journal of Nursing Knowledge, 26(2): 62-72.

McEven, M., \& Wills, E.M. (eds). (2000). Theoretical Basis for Nursing Application of Theory In Nursing Practice. Philedelphia, Lippincott Williams \& Wilkins, 24-49.

McEwen, M., \& Willis, E.M. (eds) (2006). Theoritical Basis for Nursing. Lippincott Williams \& Wilkins United States, 45-70.

McKenna, H. (2005). Theory and Research: The Releationship. Nursing Theories and Models. New York, Taylor \& Francis Group, 190-221.

Moody, L.E. (eds). (1990). Advancing Nursing Science Through Research. Newbury Park, Sage Company, 55-60.

Nieswiadomy, R.M., \& Bailey, C.A. (2017). Foundations of Nursing Research. USA, Pearson Company, 1-6. 
Aydın, R., \& Kabukcuoğlu, K. (2020). Hemşirelik araştırmalarında kuram kullanımının önemi ve süreci. Journal of Human Sciences, 17(1), 389-403. doi:10.14687/jhs.v17i1.5830

Nightingale, F. (Commemorative eds). Notes on nursing: What it is, and what it is not. Philadelphia, Lippincott, 15-19.

Özer, N. (2002). Kritik Düşünme. Journal of Anatolia Nursing and Health Sciences, 5(2):5-7.

Parker, M.E. (eds). (2005). Theories and Nursing Practise. Philedelphia, FA Davis Company, 3-21.

Parker, M.E., Smith, M.C. (eds). (2010). Nursing Theories \& Nursing Practice. Philadelphia, FA Davis Company, 152-160.

Peca, K. (2000). Positivism in Education: Philosophical, Research and Organizational Assumptions, America, Department of Education Educational Resources Information Centre, 1-35.

Pfettscher, S.A. (eds). (2014). Florence Nightingale: Modern Nursing. America, Elsevier, 71-90.

Polit, D.F., \& Beck, C.T. (eds). (2004). Foundations of Nursing Research, Philedelphia, Lippincott Williams \& Wilkins, 3-8.

Polit, D.F., \& Beck, C.T. (eds). (2008). Nursing Research: Generating and Assessing Evidence for Nursing Practice. London, Lippincott Williams \& Wilkins, 3-25.

Radwin, L., \& Fawcett, J.A. (2002). Conceptual Model-Based Programme Of Nursing Research: Retrospective And Prospective Applications. Journal of Advance Nursing, 40(3):355-60.

Scriven, M., \& Paul, R. (2004). Defining critical thinking. Statement to National Council for Excellence in Critical Thinking Instruction, Dillon Beach, CA: Foundation for Critical Thinking. Retrived: October 16, 2018. http://www.criticalthinking.org.

Silva, M.C., \& Rothbart, D. (1984). An Analysis of Changing Trends in Philosophies of Science on Nursing Theory Development and Testing. Advence Nursing Sciences, 6(2):1-13.

Sönmez, V. (2011). Pozitivizme Yöneltilen Eleştiriler. Dokuz Eylül Üniversitesi Hemşirelik Fakültesi Elektronik Dergisi, 4(1):54.

T.C. Ataturk Kültür, Dil ve Tarih Yüksek Kurumu Turk Dil Kurumu. Erisim Tarihi: 20/12/2018. http://tdk.gov.tr/index.php.

Velioğlu, P. (1999). Hemşirelikte Kavram ve Kuramlar. İstanbul, Alas ofset, 372-399, (1999).

\section{Extended English Summary}

Nursing is a health discipline based on philosophy, theory, research and practice. The theories shed light on the formation of knowledge of this health discipline, the determination of research methods, the realization and application of the research process systematically. Theories are very important in determining the problem, how the problem will be solved and how this solution will be transferred to the application. In order for a knowledge to be scientific, it must be based on systematic foundations. In order to develop a professional nursing profession and education, undergraduate and graduate education should be theory based. Professionals should understand the theories in undergraduate education and internalize them, do theory-based research in graduate education, should try theories through research and develop new theories in doctoral education. In this way, the scientific foundations of the nursing profession will be strengthened. In this review, information about the use of theories in nursing research, the importance and limitations of the use of theory are presented.

In order for any discipline to become a science, it is necessary to produce knowledge after the research and application process. The fact that nursing discipline is a science has been the result of knowledge specific to nursing (Velioğlu, 1999). The knowledge of nursing constitutes the science of nursing. Discipline-specific knowledge production and accumulation can be realized by deciding the problem in the light of theories, solving the problem with theory-based research, testing and developing theories. There is a mutually dynamic process between theory and research: it supports research theory, the theory produces the research question, and guides the research process (Fawcett, 2005; McKenna, 2005; Parker, 2005). Jacox (1974) stated that theoretic research is as follows; "A conducted research without theory is similar to a team of unplanned bricks stacking 
Aydın, R., \& Kabukcuoğlu, K. (2020). Hemșirelik araştırmalarında kuram kullanımının önemi ve süreci. Journal of Human Sciences, 17(1), 389-403. doi:10.14687/jhs.v17i1.5830

bricks, each unaware of each other, the bricks throwing bricks in pile, but they don't even know how a house will emerge." Nursing knowledge produced without theory is only a collection of statistical and observational data that are not consistent and understandable (Moody, 1996).

Regardless of how much information is available, information that is not understood and not used in practice consists of a pile and only a small part of it is used. Knowledge is gained through research and understood through theories (Alligood, 2014). This interrelation can also be described as follows: Applications should lead to the development of theories, theories should be tested through research, developed, led to research, and theories should return to research and practice. Unfortunately, this three-way interaction between theory, research and practice in nursing does not function simultaneously. Worst, practices take place without guiding a theory or research. The majority of nursing research is descriptive. Theoretical studies are weakly linked to the theory and continue to be carried out without guidance (McKenna, 2005; Alligood, 2014).

According to Oliver Slevin'e (1996) 'Theory, research and practice are three dancers. They are all influenced by each other, and they all make each other appear. Dancers interact to produce a systematic, aesthetic beauty and elegance. A weak dancer who stumbles or does not undertake appropriate moves cannot move and adversely affect others. Such a clear journey will cause a short journey. Therefore, all three dancers must be strong and talented." Similarly, weak theory studies or inadequate research practices may lead to the death of a discipline of nursing. It is the duty of our nurses to keep these three dancers strong and to make them interact properly (McKenna, 2005). Brown (1964), While nurse researchers is planning research, they have to ask questions; In what way and to what extent is this research relevant to theory? What contribution does this research make to scientific knowledge? Theory development research: Theory development research is conducted to explain and explore events. The theories are revealed by an induction approach. Therefore, researchers should be aware that nursing care is very important for the collection and observation of information in the theory production process. Theories can be produced through both qualitative and quantitative research (McKenna, 2005).

Theory-based research: In theory-based research, the aim is not to develop a new theory, nor to determine the validity of the existing theory. The aim is to present the conceptual framework of the research and to discuss its theoretical framework. At the same time, to make all stages of the research within a conceptual framework and to make sense of it (Moody, 1990; McKenna, 2005).

Theory-testing research: Theory-testing research is conducted to determine the validity of the existing theory. In theory-testing research, research methods explore how accurately the theory portrays real-world phenomena and relationships. Theory cannot be tested by research as a whole. Because not all concepts have empirical indicators (McKenna, 2005). Testing the theory involves a deductive approach. Hypotheses should be tested with randomized controlled trialsResearch questions or hypotheses should be derived from concepts in theory. There must be a meaningful coherence between the conceptual structure and the study design. If the researcher is conducting research that tests theory: Is the research designed to show the relationship between hypotheses/research questions and theory? Is research supported by theory? Is it a source of information for theory or basic research questions or hypotheses? The answer should be sought for these questions (Fawcett, \& Downs, 1992). As in all studies, data collection tools are very important in theory-tested studies. The selected sample should be carefully selected and the sample size should be determined by power analysis. The analysis should focus on whether the data provide sufficient quantitative evidence to support or reject hypotheses (Parker, 2005).

In order to contribute to the development of nursing profession and education, it is recommended to use nursing theories and models in nursing graduate theses. Since the development of professional knowledge and contribution to the profession should now be gained in doctoral level education, the use of theories and models should be expanded. In addition, nurses' mastery of nursing theories is very important in order to adapt the theories and models to research and practice. 